\title{
Development of Online Learning Platform for Thai University Students
}

\author{
Wirapong Chansanam, Kulthida Tuamsuk, Kornwipa Poonpon, and Treepidok Ngootip
}

\begin{abstract}
It is very challenging to regulate emerging innovations in the rapid evolution of online education, especially during the pandemic of Covid-19. Modern online learning systems must take both educational and technological factors into account. For learning purposes, universities have attempted to facilitate their students with online learning practices and phases using emerging technologies. In this study, the online student platform for humanities and social sciences students (HUSO-OPS) was developed using the user-centric, TPACK, and V-model design. Especially, the V-model mostly focused on the field of app engineering online learning network coordination. The 5-axis framework was to enhance the TPACK model to address online learning in more detail about pedagogy, content, movement technology, and the learner profile. The development also concerns the content as well as the context of learning. This research demonstrates the outstanding use of the HUSO-OPS platform during the global pandemic of Covid-19. They explain the different factors involved and the successful interconnections needed for optimum and efficient online learning implementation. The balance of the five parts on the online learning platform in design or consultation is a plural reflection matter.
\end{abstract}

Index Terms-Digital learning, online learning platform, higher education.

\section{INTRODUCTION}

Digital communication technology is a key factor in the 21 st-century learning environment. Teaching and learning must focus on the innovative use of technology innovations. Therefore, two items are required to create a much-desired educational environment for our information era cardinal citizens (21st-century learners). Firstly, the provision of necessary ICT infrastructure and facilities and the use of teaching and learning facilities were made by lecturers. The second aspect is for faculties to adopt teaching strategies and practices in their classes into the 21st century. Lecturers and technologies are also important factors in the 21 st century learning climate. The basic ICT infrastructure and amenities of the modern learning environment go far beyond the provision of Internet connectivity and one or two conference rooms besides educational institutions. Unlimited one-on-one access to a computer and internet connection for lecturers and learners during classroom instruction is necessarily required as part of the basic facilities needed for all learning levels. Responding to this as a fundamental need

Manuscript received January 3, 2021; revised March 11, 2021. This work was supported in part by the Faculty of Humanities and Social Sciences, Khon Kaen University under Grant HS2563.

The authors are with the Faculty of Humanities and Social Sciences, Khon Kaen University, Khon Kaen, 40002 Thailand (e-mail: wirach@kku.ac.th, kultua@kku.ac.th, korpul@kku.ac.th, treejarpus88@gmail.com). for academic institutions is a worldwide challenge [1].

By the end of 2019, Coronavirus (Covid-19) began to spread rapidly and eventually became a pandemic worldwide. A large-scale pandemic impacts public well-being and many facets of daily life, including healthcare and education [2]. In several nations, health officials' advice pushed the education system to consider a face-to-face solution. The learning process should be continuous in case of disruption [2]. The quick, simple alternative is going from face-to-face lectures to electronic meetings. The altitude learning approach may well be the best alternative for compelled students [3]. Inadvertently, this pandemic has expanded knowledge and technological penetration in schooling that is already accessible [4]. In addition, it claims that the electronic learning cycle should provide a) secure contact network, b) suitable online learning facilities, c) comfortable learning platforms, d) efficient learning strategies, e) educational institutions, f) efficient support systems for lecturers and learners, and g) strong cooperation between parents, lecturers and students (P-L-S cooperation).

As online education has changed rapidly during the spread of Covid-19, the present study manifests the development of an online learning platform to facilitate university students during the Covid-19 impediment at Khon Kaen University, Thailand. The paper describes the planning and implementation of a basic content management framework for digital learning entitled the Humanities and Social Sciences Online Platform for Students (HUSO-OPS). The HUSO-OPS aims to promote digital channels' growth and production for inclusion and use in the educational standards at the Faculty of Humanities and Social Sciences (HUSO), Khon Kaen University (KKU). The program is open and suits all types of display on different devices, e.g., perpetual pcs, notebooks, and mobile devices (tablets and smartphones). A production process is an effective approach that meets the idea of user-centered architecture. The electronic learning platform's design improves the downside, though, and creativity capabilities of higher education learners and offers a great potential to facilitate skill growth. Little is known, however, about how the systems influence the acquisition of skills.

In this article, the two-phase development of the platform is illustrated. The first phase discusses the specifics of the guidance on the design and creation of communication structures that would contribute to the growth and development online for the students of the Faculty of Humanities and Social Sciences, Khon Kaen University, Thailand. Within this, three separate main modules and their features and functions are revealed to the extent that they allow it possible for more professionals to operate on a 
common board. The second phase shows the platform's implementation at HUSO and the users' evaluation of the use of the platform.

\section{LITERATURE REVIEW}

Many educational organizations and government groups are making continuous efforts, and vast resources are now being used for students' or workers' electronic learning opportunities. Networking organizations are rapidly generating new ways to ensure that educational development is effectively accessed digitally [5]. Accordingly, the user pool has grown from conventional students to various employees or workers, as seen in Huge Free Online Classes [6]. In institutional contexts, these free online classes are the most common forms of online education. The Management Systems of Learning (LMSs) Lujan-Mora, S. Moodle [7] is especially taught as a type of content management system (CMS). Based on the different interpretations [8] of the structures and their key features, they are built to include cost-effective high-scale schooling cohorts. They are famous for advancing blended learning in secondary schools, public organizations, private companies, or comprehensive online learning. Such approaches are useful for broad organizations because lecturers and administrators can track participants' requirements to learn output. They will have the ability to receive any updates on learning performance at the core of current programs, approaches, and development in the organization. However, they do not have a platform to do any other works, and researchers also suggest that these institutional systems are not yet in compliance with the standards. Other weaknesses also included high support and sales costs, unusable interface due to limited number of screens, compatibility with smart devices, students' rejection of mandatory software, and students' limited ability to take on developer roles despite learning enhancement objectives [9]-[11]. In response to these problems, online learning platforms have been developed to provide online learners with an alternative to the conventional ways of receiving information across typically large e-learning networks [12]. As a new type of digital instruction, the online learning platform can facilitate learning because of its convenient usability and ease of integration with virtual environments and online training systems.

\section{A. The TPACK Framework}

Based on the Shulman model, the 'Technological, Pedagogical, Content Knowledge' TPACK method was adopted [13]. In this model, three circles were introduced, instead of the two circles in the original model [14]. As a learning facilitator in the first two education and materials areas, Mishra and Koehler also used technology. In this new model, which is defined by PCK, TCK (Scientific Containment Knowledge), TPK (Technological Pedagogical Knowledge), the three circles must coordinate to ensure the successful incorporation of technology into learning. Interactions within these bodies of information are equally essential. The three circles must communicate in a cooperative manner (Fig. 1).

TPACK has become one of the most influential technological integration theories in education since its first publication in 2006. The components mentioned above remain accessible to a variety of educational circumstances. At many junctions in their environments, this model's flexibility can be seen, allowing researchers to adapt it to different situations.

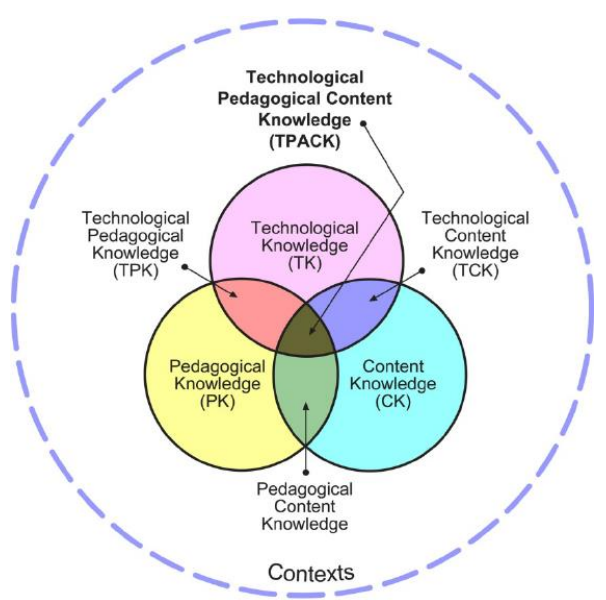

Fig. 1. The TPACK Framework by Mishra and Koehler (2006).

\section{B. Electronic Learning (e-Learning)}

These days, with the innovation of educational technology, e-learning, as a new instruction method, is becoming increasingly common in education at all levels. A survey in the US in 2015 showed that the number of students taking online classes increased from $3.7 \%$ to $3.9 \%$. One in four students took at least one online course in one year. Sixty percent of academic leaders considered that e-learning would be important for long-term growth [15]. However, while e-learning is a hot subject, e-learning is often complementary to schooling [16]. Nevertheless, the available studies have proved that e-learning is effective. There are insignificant differences in course scores, student engagement, and student satisfaction between online and offline learning methods.

\section{Website Design}

The architecture of the Website plays a significant role in online shopping, as it affects consumers directly during the purchase cycle. The product's features determine how the user knows the online market. A well-designed website decreases processing time and avoids an inability to obey. The architecture of sites affects loyalty to consumers [17], [18].

\section{Website Security}

Transaction confidentiality and consumer data protection are the key issues of online consumers purchasing goods and services [19]. For this purpose, e-commerce typically requires a privacy policy for how to handle customer details. It is achieved in such a manner that customers are more confident in moving to purchases. Throughout the study about the impact of information behavior online towards customer loyalty in mobile applications, the researchers claimed that protection is the aspect that most affects customers when determining whether to make an online purchase [18].

\section{E. Information Quality}


Knowledge plays an important role in shaping consumer behavior in the decision-making phase as it can direct consumers towards making a purchase despite there being no physical contact with the company in the online world [20].

\section{MATERIALS AND METHODS}

There are distinctive terminologies used to describe instructional programming programs, such as e-learning systems, learning management systems (LMS), content management system tools (CMS), and the digital learning environment. The present portal enables students to view course material in several formats (e.g., text, visual, photos, sound) and to communicate with all instructors and associates via texts, meetings, chats, video meetings, or a range of customized apps [21].

\section{A. The Frameworks of the Study}

1) Web-based research and configuration of computer frameworks

No previous deep computer technology skill is needed to use the guidance of the digital learning framework. The present system enables lecturers to generate and add web-based and intelligent device-based equipment quickly. There are three features in the system, one for the system administrator, another for the faculty staff, and the other for users or students. First, the Administrator System is for the program administrators who act as system managers to manage basic system information, such as news, events, classes, programs, portions, students, and lecturers. The administrator system is also used to stimulate or disable systems, import or export database systems, and enable user roles and password changes. Second, the Staff User System provides the faculty and staff with different resources for handling program facilities, including interactive materials, software, and course reviews. Staff users can also change the passwords of their accounts. The third feature is the Student System that can offer students digital resources for uploading assignments, previous tests, analysis papers, and downloading all other data submitted by instructors. It also helps individuals to reconfigure the status of the students. Students can access the internet to display their web-based classes on and off universities.

2) The V-model

The V-model was adopted to design and develop the platform of the study. Five aspects were taken into consideration for this adoption.

a) Adopted System Life Cycle Model

There are different approaches for creating a life-cycle method for the smartphone. The growing approach is intended to offer a clear interpretation of the activities or occurrences throughout the system's life cycle. The method includes converting the users' desires into program specifications. Such specifications are then translated into a specification accompanied by the execution of the code. The technology incorporated is then checked and mounted. In the end, the built program should be tested for frictionless running. Moreover, a multitude of such tasks can be combined and carried out iteratively [22]. The question of identifying and soundly associating the various tasks was thoroughly studied. Several models have been proposed to address this issue. Ultimately, the V-model was chosen for the system life-cycle design process (see Fig. 2). The V-form may be considered within the context of the configuration of the Fountain [23].

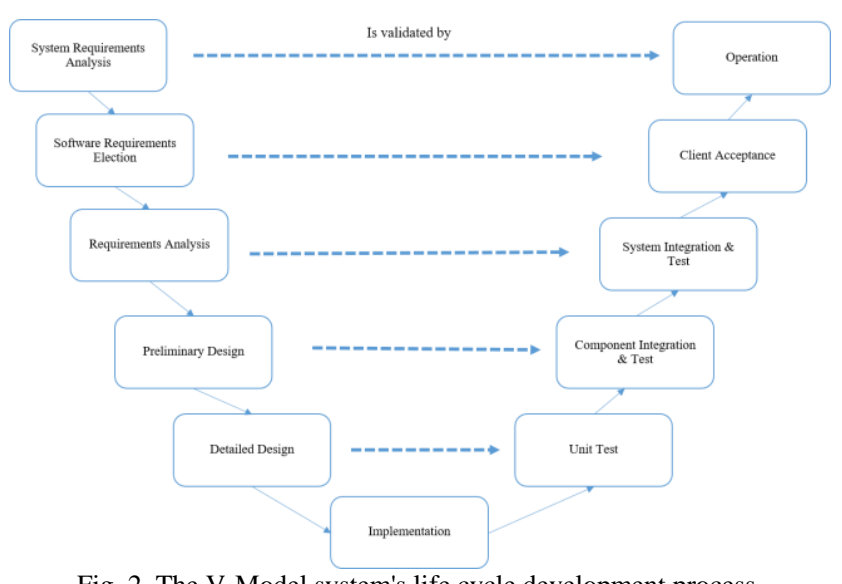

Fig. 2. The V-Model system's life cycle development process.

\section{b) System Analysis}

Details of the software system must be identified during the analysis phase. The key goal of this process is to develop the method. A set of devices, such as infographics, system activity diagrams, class diagrams, is used to record technical requirements. To perform the task requested, the object of the structure under design offered different perspectives and unique requirements. Also, system feasibility has to be analyzed. The analysis of system feasibility for the HUSO-OPS platform is described as follows.

Since professional teaching has been strongly promoted in Thailand during education reform, many organizations have developed their online education programs. However, students do not regularly access or use these operational structures and their associated portals because their contents, formats, or input processes do not meet current university students' needs. This suggests that the current curriculum structures cannot fulfill the demands for instruction and social skills. The development of the HUSO-OPS may shed light on these three aspects.

- Facility of operational management. The mindset and program awareness of university administrators, lecturers, and studies show operational management's viability. The web-based learning system offers rich and complete knowledge compared to conventional learning systems, promotes today's students' learning interests, and highlights comments and communication between students and lecturers, students, lecturers and parents, and lecturers. As a result, the application, which has brought forward logical management strategies, has received support from university administration, lecturers, friends, and students. Therefore, in the field of operational management, the development of the system is feasible.

- Technology application feasibility. The HUSO-OPS platform is precisely the same as the new software engineering and website creation when it is implemented functionally. The development of software technologies has grown relatively mature with the rapid growth of Internet technology. Universities, meanwhile, are the strong-holds of software professionals as 
knowledge-intensive locations. Theoretically, the proposed software may also be implemented.

- Economic viability of advantages. The program's economic benefits are measured by construction costs and economic advantages following growth. Successfully, system implementation combines teaching capital, improves education and social gaps, and saves human, material, and financial energy. It is, therefore, economically advantageous if the software is enforced.

c) System Requirements Features

The necessity of our web-based e-assessment arrangement is functional, based on the actual teaching requirements of faculty members. Technical specifications are the definition, without regard for execution, of systems experiences with the world (i.e., termination user and other outside structures). Our system offers different services for each user, as described below.

The administrators can sign in (as System Administrator), switch on or off the machine, renew data, manage the system's core information, e.g., adding, apprising, deleting and/or displaying the content, and manage user changed or new password.

The lectures and supporting staff can log-in (as Faculty and Staff), modify a password, and handle all device resources, e.g., attaching, editing, uninstalling files, displaying information, creating test queries, quizzes, preliminary tests, and model responses, etc.

The Student can log-in (as Student), adjust the code, get a verification code instead of destroying it, and access educational materials, coursework, documentary review, tutorial videos, prior reviews.

d) System Design

The system's design aims to be easily accessible and personalized for all users. In order to achieve entry across the Website, the program is a web-based application. Many other associated issues need to be addressed.

\section{- Designing methodology and patterns}

The production period of applications (methodologies) is split down into methods and techniques (see Fig. 3). The architectural framework explains how objects or classes communicate and connect. This sequence is not that in, which can be shifted to a code. It is a foldable approach, not a completed model.

- Designing function modules

The basic steps in developing online education platforms are prerequisites, design, programming, development, and testing. Before designing our function modules, we need to collect needs from our stakeholders. The Unified Process Model (UML) is one of the most common conventional frameworks for comprehensive software design. This allows us to understand the varied needs of the consumers.

UML description is independent of the channel and terminology used [24]. In this portion, all program features should be defined following functional and non-functional specifications. It starts with requirements, non-functional needs, and different use cases and their diagram modeling.

$>$ Operational specifications. Technical or economic paths are behavior that the application follows to become an application.

$>$ Non-functional specifications. These are the needs that describe the structure. There are requirements for output, technical equipment, or construction style. Such specifications may involve design limitations (e.g., programming language, RDBMS model, operating system model, and computers). The program has to be expandable as part of this function, i.e., it potentially incorporates or changes additional functions.

$>$ Authentication. The HUSO-OPS needs to be extremely secure since the details are expected not to be available to anyone.

$>$ Ergonomics. The HUSO-OPS is to have an easy-to-use, transparent, and user-friendly graphical user interface.

$>$ Field Control. The HUSO-OPS provides an input to avoid the working of knowledge that does not suit the max field.

$>$ Identification of use cases. The use case is a series of sequences of actions carried out by an application that gives a measurable outcome of interest to a single actor. The use of case descriptions is a function of the system. It deals with actor/system relations and adds "relevant" significance to the actor [25]. With regard to our structure, Fig. 3 indicates a global UML case diagram of our developed process. There are seven examples of use, and one person in the 'HUSO-OPS' provides results. Actor User logs in to the program (Sign up) by filling in detailed information, such as his e-mail address and password). Upon registration, the users sign up for the scheme by sending an e-mail to the organization (@kku.ac.th). Once linked to the channel, the user can take advantage of the features accessible on our system, i.e., developing any material or courses.

- Relational database design

The Server is known to be a core component of our application. It can be achieved by using the MySQL database. The transactional database schema (RDBMS) is required to meet all system requirements. RDBMS records all the details necessary for a web-based assessment and management system, such as news, media, teaching materials, evaluation, tutorials, question types, pre-tests, quizzes, classwork, and general knowledge for administrators, lecturers, and students.

- Application logic design

This part mainly deals with three sub-parts of system design:

$>$ The design of the architecture (i.e., tiers and layers of the system).

$>$ b) The higher-level architecture (i.e., the recognition and configuration of the various subsystems).

$>$ c) Comprehensive template (i.e., series diagram, class diagram).

e) System Architecture

The HUSO-OPS consists primarily of three parts, namely the user, the database, and the RDBMS. Web-based assembly languages such as PHP and Java scripts have been used to construct the client-server architecture. The user-side software also acts as a link between the user and the application. The MySQL Database System retains and 
handles school information and course material. Linux Server is a platform that can be used to manage databases and web programs.

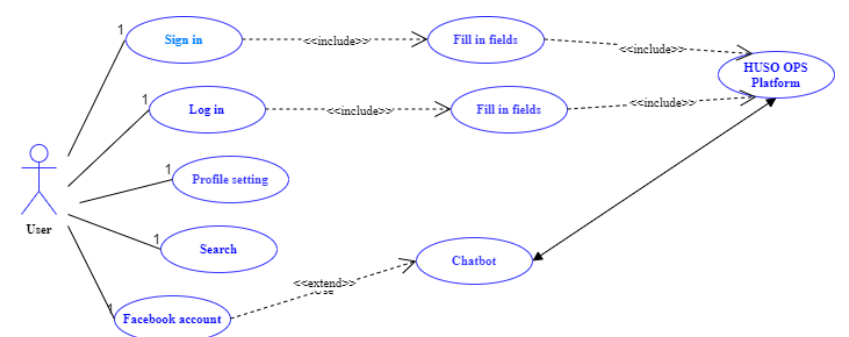

Fig. 3. Representation of global use case diagram of HUSO-OPS.

With this 5-axis framework, the HUSO-OPS platform was developed and illustrated as follows.

\section{B. The Developed HUSO-OPS Platform}

This part shows the developed model and features of the HUSO-OPS platform.

1) Online learning platform model

This model focuses on textured technology to generate and set up an interactive education dungeon crawling-Tier design. It is an industry-standard infrastructure model that is ideal for supporting client/server applications on project time. It is also used to identify scalability, security, evolutionary low latency [26], [27]. Fig. 4 shows the HUSO-OPS site diagram for build the website structure.

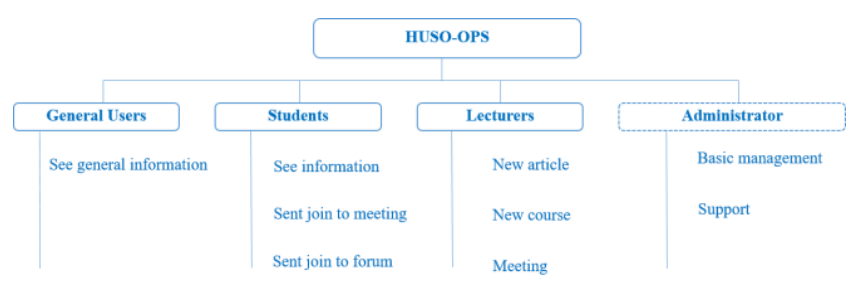

Fig. 4. Block diagram of HUSO-OPS.

2) Online platform development

This segment is devoted to discussing the results of the development and implementation of our initiative. The primary devices of the HUSO-OPS, as well as the description of each interface, are presented. The online platform involves both front-end and back-end applications. The back-end applications adjust the interface's size to fit computers and devices with varying screen sizes (as shown in Fig.7) . Fig. 5 shows the full responsiveness of a typical title tag for lecturers displayed on laptops and smart devices.

3) Interface display

The HUSO-OPS is presented as a web page after the user has logged in. The main modules are covered on the homepage, including the lecturer module, student module, and interactive platform. Depending on the requirements, the user clicks to enter the subsystem and obtain the necessary learning and knowledge materials. The homepage also contains two control windows for both intercollegiate and external information. These windows were designed to help students appreciate and increase their interest. In advisement, the homepage includes a search feature and an exchange bar. In the search field, the user must test the specifics of the keyword. If the user is interested in any knowledge or learning materials, they can share contacts with other university users by clicking the sharing icon. Fig. 6 is a screenshot on the HUSO-OPS homepage.

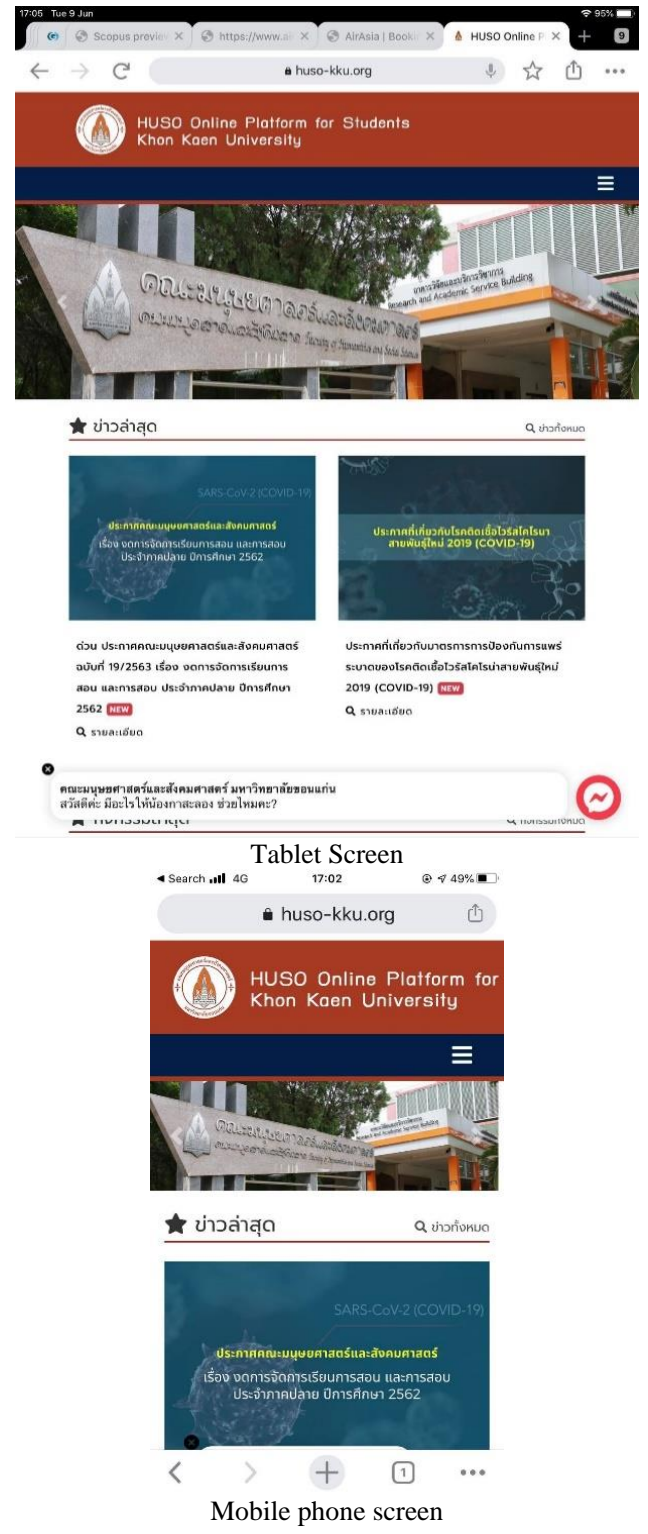

Fig. 5. The responsive design of a typical content page for HUSO-OPS

The user can click and enter any of the three sections of the HUSO-OPS homepage. For example, this module includes information on faculty information, course information administered to the respondents interested in existing university students. There is a meeting room on the board where students can share their preferences and opinions. The purpose of this module is to build a relaxing environment for students to learn while having fun. The Screenshot of the Interest Module is shown below in Fig. 6.

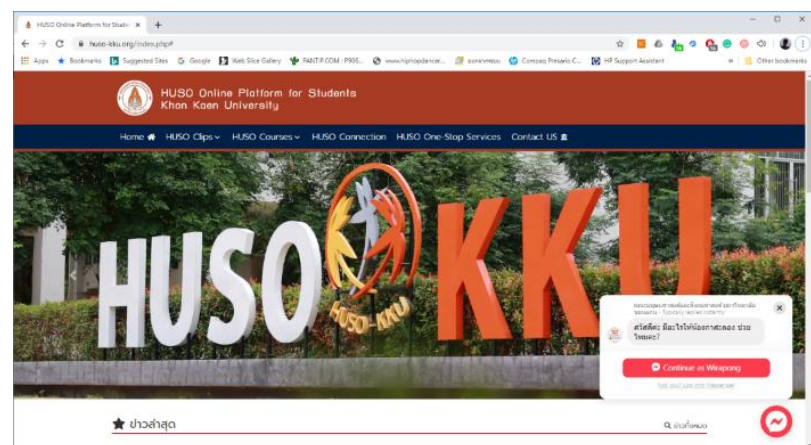

Fig. 6. The main interface front-end of HUSO-OPS. 


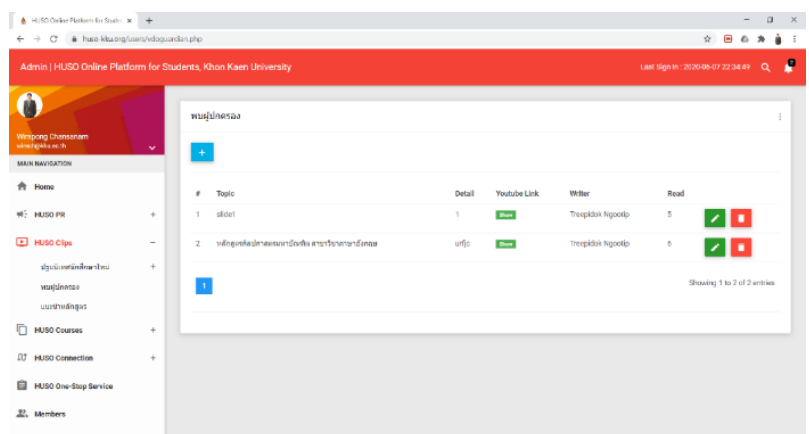

Fig. 7. The main interface for the System Administrator of HUSO-OPS.

\section{4) Chatbot feature}

When the user uses HUSO-OPS, concise and relevant answers must be given. This ensures that a question answering system is easily integrated into the conversational function of the chatbot. Chatbots have arisen mainly from computer science and have been used by businesses to have a comparative edge on the internet. Still, learners' presence and knowledge retention by chatbots have been successfully expanded in the sense of teaching. The Chatbot screenshot is shown in Fig. 6.

In addition, enhanced problem-solving, understanding, improved memory, response to individual bond requisites during learning, more superficial interaction and information procedures, motivation for key learning behaviors, an increased sense of security and simplicity in the learning context, as well as enormous enthusiasm, all stand to gain through the use of chatbots and some other educational institutions.

\section{The Implementation of the HUSO-OPS Platform}

The HUSO-OPS platform was launched in June 2020, during the Covid-19 period, for all users of the Faculty of Humanities and Social Sciences, Khon Kaen University. It had been evaluated by 30 faculty members and 40 undergraduate students who used the platform. Testers were required to sign in and use all computers and smart devices during training. An online questionnaire via google form was used to collect the data from lecturers and students regarding the HUSO-OPS's effect on the users.

\section{RESUlTS AND DISCUSSIONS}

After collecting data regarding the HUSO-OPS validation and evaluation, the online questionnaire results were shown in Table I. Table I displays the 10 questions posed and the replies given by the participants [28].

TABLE I: RESULT OF RATINGS ON HUSO-OPS BY THE 70 PARTICIPANTS

\begin{tabular}{|c|c|c|c|c|c|c|c|}
\hline \multirow[t]{2}{*}{ Questions Topic } & \multicolumn{5}{|c|}{ Scale } & \multirow[t]{2}{*}{ Total } & \multirow[t]{2}{*}{$\%$} \\
\hline & 5 & 4 & 3 & 2 & 1 & & \\
\hline Easy to use & $50(71.43 \%)$ & $20(28.57 \%)$ & & & & 70 & 100 \\
\hline Efficient in performing evaluation & $45(64.29 \%)$ & $20(28.57 \%)$ & $\begin{array}{c}5 \\
(7.14 \%) \\
\end{array}$ & & & 70 & 100 \\
\hline Good Interactive & $52(74.29 \%)$ & $18(25.71 \%)$ & & & & 70 & 100 \\
\hline Well organized content & $43(61.43 \%)$ & $20(28.57 \%)$ & $7(10.00 \%)$ & & & 70 & 100 \\
\hline Easy to move around the website & $48(68.57 \%)$ & $20(28.57 \%)$ & $\begin{array}{c}2 \\
(2.86 \%) \\
\end{array}$ & & & 70 & 100 \\
\hline Attractive user interface design & $55(78.57 \%)$ & $15(21.43 \%)$ & & & & 70 & 100 \\
\hline $\begin{array}{l}\text { Easy to read and comprehensible } \\
\text { content }\end{array}$ & $52(74.29 \%)$ & $18(25.71 \%)$ & & & & 70 & 100 \\
\hline $\begin{array}{l}\text { Clear and easy to understand } \\
\text { navigator }\end{array}$ & $50(71.43 \%)$ & $18(25.71 \%)$ & $\begin{array}{c}2 \\
(2.86 \%) \\
\end{array}$ & & & 70 & 100 \\
\hline $\begin{array}{l}\text { Feel in control when using } \\
\text { HUSO-OPS }\end{array}$ & $56(80.00 \%)$ & $14(20.00 \%)$ & & & & 70 & 100 \\
\hline $\begin{array}{l}\text { Gain a better understanding of } \\
\text { usability after using HUSO-OPS }\end{array}$ & $60(85.71 \%)$ & $10(14.29 \%)$ & & & & 70 & 100 \\
\hline
\end{tabular}

Overall, participants were satisfied with the HUSO-OPS. The mean value for positive feedback given to the ten questions is more than $92.00 \%$. This is an acceptable result, but improvements could be made to the content organization, system efficiency, and navigator features. More than $2.00 \%$ of the participants give neutral feedback to these three aspects. The HUSO-OPS score evaluated is shown by the chart in Fig. 8.

Qualitative results also verified that HUSO-OPS is widely recognized to understand functionality better when the HUSO-OPS is used for both lecturers and students. The study participants admired the elegance of the functionality, the clear design, and the affordability of material, and the possibility of interaction through the forum. Regarding the weaknesses of the HUSO-OPS, there was a considerable number of comments. The input received is used to determine which suggestions apply to the situation and may offer further improvement of the program's efficacy. For example, an expanded letter size may be used for text for webpage material, or users might be provided the option to apply the same size of the text to the target production. In order to make a final decision on the redesign, it is important to discuss all issues identified by the users. As a result, the failure to handle the location of components on the web page is perceived to be less important than a possible poor layout on tiny screens of smart devices.

Other issues apart from usability have been reported in the evaluation. In particular, they are related to the management of the meeting's function, its respondents, and plans for the entire length of the discussion. Score reporting right after the appointment was suggested to be included in the meeting feature. Other additions to the application include apps for lecturers to help, for example, monitoring classes, recording their progress and success throughout courses, and apps for 
learners to show their completion on the assignment. These suggestions could be used to improve the HUSO-OPS if the Faculty has a plan to shift the platform for formal online learning.

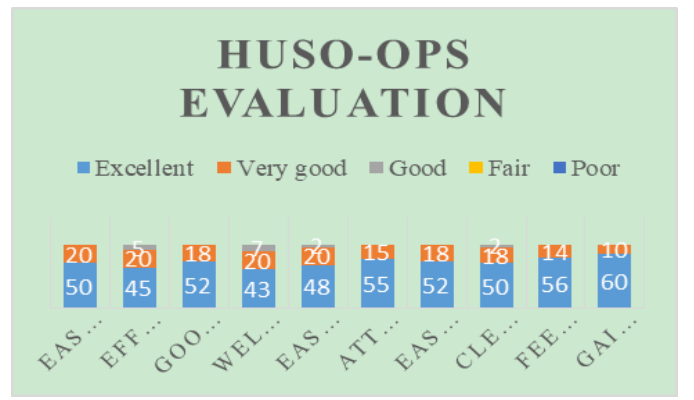

Fig. 8. Graph of rating results on HUSO-OPS by all 70 participants.

Concerning the research process, it should be remembered that some of the user interface findings could be the product of a bad implementation of the learning mate-rial of certain topics. Many users who have taken the status with lecturers are not familiar with educational design concepts and have not implemented them. While these users may assess the instructor system's user experience, especially when creating informal learning animations, their topics could have significant content-related quality flows. However, the study indicates that students who determine the quality of learning activity have trouble deciding which issues are linked to accessibility and linked to enhancing the material.

This limitation can be settled so that the ill-planned subjects are withheld from the second part of the study. This method involves assessing courses prepared by training assessment professionals before the user interface accessibility analysis. One solution would be to engage only lecturers or training developers to develop courses online during the first component of the research. Both options support the original design that the HUSO-OPS should be available to everyone, which means that someone can create content for activities. This includes a matter of their own choice. Both approaches often ensure that the program's high degree of accessibility improves the cycle of knowledge development and learning.

There are several implications from the development and the implementation of the HUSO-OPS platform. For several graduates, studying through and from others is a popular form of study. The HUSO-OPS allows students to develop knowledge and abilities with teamwork. Our developed online educational platform is used as a learning opportunity to foster university collaboration, communication, and connectivity skills and competence HUSO-OPS in separate communities. The study results also guide the improvements to the next iteration of the user-centered HUSO-OPS design. Based on the results, the evaluation process has shown that it is appropriate for the iterative step of value chains between CMS research and innovation, theory, and new technologies. The research indicates that the usability assessment can be implemented easily and cost-effectively in the design phase. In addition, the HUSO-OPS may be further modified and optimized to satisfy the specifications of the unique online learning framework built for study, thus leading to the design and improvement of the online learning platform for scholars and scientists.

This paper is also advantageous in illustrating a systematic analysis of electronic learning and creating the online learning network framework utilizing the integrated design of the CMS and the growth of the self-domain. The philosophical parts of the classrooms are presented by the LMS requirement, which enables 1) Management of accounts, 2) Protection of security, 3) Collaborative curriculum, 4) Collection of student conduct, and 5) Set of reviews. Detailed solutions to this method shall be considered and examined in depth. A more immersive and user-friendly learning interface has been developed to promote education and use it in all educational institutions.

For future research, suggestions for further studies would be an application of the present model to develop a similar kind of platform focusing on incorporating learning analytics that includes opportunities to track student experiences and group activities and monitor student involvement evolution. Our established interactive learning interface has been used as a learning opportunity to foster university collaboration, communication, and connectivity skills, and competence HUSO-OPS in separate communities, thus improving feedback and providing strategic recommendations to improve results.

\section{CONCLUSIONS}

This article describes the method of planning, creating, and implementing an online application project named the HUSO-OPS, a responsive web for coherent education and learning during the Covid-19 at the Faculty of Humanities and Social Sciences, Khon Kaen University, Thailand, as a case study. The process begins with gathering online education network needs and identifying all its positions by the Dean and an associate dean during the crisis of Covid-19 to facilitate learning and teaching. The iterative cycle of user-centered architecture, the TPACK system, and the $\mathrm{V}$-model was used to design, prototype, and pilot the platform's first design. A detailed usability analysis had also been carried out to assess the framework created. The second version focuses on user insight, and the integration follows. The assessment tool has combined several well-known and reliable accessibility testing and functionality evaluation methods. The results of both the design and development of the platform and its implementation were reported. In particular, first, the Unified Process Model (UML), PHP and Java scripts for computer languages, and MySQL for database engine management, and HUSO-OPS concept used in the web-based platform were reported.

Second, the platform implementation evaluation was conducted with the users, which included faculty, staff, and students at the Faculty of Humanities and Social Sciences. Quantitative tests indicated that the accessibility rate reached an exceptional point. Qualitative reviews from users showed a variety of accessibility problems as well as other information quality concerns. The results also show that the developed HUSO-OPS can increase students' satisfaction and academic performance and promote cooperation between them during the Covid-19 pandemic. 


\section{CONFLICT OF INTEREST}

The authors declare no conflict of interest.

\section{AUTHOR CONTRIBUTIONS}

Wirapong Chansanam and Treepidok Ngootip conducted the research; Kornwipa Poonpon collected and analyzed the data; Kulthida Tuamsuk gave guidance on the conceptual research; all authors had approved.

\section{REFERENCES}

[1] S. A. Garba, Y. Byabazaire, and A. H. Busthami, "Toward the use of 21st Century teaching-learning approaches: The trend of development in Malaysian schools within the context of Asia Pacific," International Journal of Emerging Technologies in Learning, vol. 10, no. 4, pp. 72-79, 2015.

[2] R. H. Huang, D. J. Liu, A. Tlili, J. F. Yang, and H. H. Wang, Handbook on Facilitating Flexible Learning during Educational Disruption: The Chinese Experience in Maintaining Undisrupted Learning in COVID-19 Outbreak, Beijing: Smart Learn. Inst. Beijing Norm University, 2020.

[3] G. Basilaia, M. Dgebuadze, and M. Kantaria, "Replacing the classic learning form at Universities as an immediate response to the COVID-19 virus infection in Georgia," International Journal for Research in Applied Science \& Engineering Technology, vol. 8, no. 3, pp. 101-108, 2020.

[4] P. S. Goh and J. E. Sandars, "A vision of the use of technology in medical education after the COVID-19," MedEdPublish, vol. 9, no. 1, p. 49, 2020.

[5] Y. I. Daradkeh, V. A. Testov, and O. B. Golubev, "Educational network projects as form of E-Learning," International Journal of Advanced Corporate Learning, vol. 12, no. 1, pp. 29-40, 2019.

[6] S. Sanchez-Gordon and S. Lujan-Mora, "Technological innovations in large-scale teaching: Five roots of massive open online courses," Journal of Educational Computing Research, vol. 56, no. 5, pp. 623-644, 2018

[7] M. Dougiamas. (2020). Moodle. [Online]. Available: https://moodle.org

[8] S. H. Alshammari, M. Bilal Ali, and M. S. Rosli, "LMS, CMS and LCMS: The confusion among them," Science International, vol. 30, no. 3, pp. 455-459, 2018.

[9] K. D. Strang and N. R. Vajjhala, "Student resistance to a mandatory learning management system in online supply chain courses," Journal of Organizational and End User Computing, vol. 29, no. 3, pp. 49-67, 2017.

[10] K. Schoepp, "Barriers to technology integration in a technology-rich environment," Learning and Teaching in Higher Education, vol. 2, no. 1 , pp. 1-24, 2005.

[11] T. M. Al Meajel and T. A. Sharadgah, "Barriers to using the blackboard system in teaching and learning: Faculty perceptions," Technology, Knowledge and Learning, vol. 23, no. 2, pp. 351-366, 2018.

[12] Y. Park and Y. Kim, "A design and development of micro-learning content in e-learning system," International Journal on Advanced Science, Engineering and Information Technology, vol. 8, no. 1, pp. 56-61, 2018.

[13] M. J. Koehler and P. Mishra, "What is technological pedagogical content knowledge (TPACK)," Contemporary Issues in Technology and Teacher Education, vol. 9, no. 1, pp. 60-70, 2009.

[14] P. Mishra and M. J. Koehler, "Technological pedagogical content knowledge: A framework for teacher knowledge," Teachers College Record, vol. 108, no. 6, pp. 1017-1054, 2006.

[15] S. Chakravorti, "Student satisfaction and learning in online classes: The case of a US Midwestern," Association of Marketing Theory and Practice, vol. 42, 2019.

[16] L. Zhou, S. Wu, M. Zhou, and F. Li, "School's out, but class' on', the largest online education in the world today: Taking China's practical exploration during The COVID-19 epidemic prevention and control as an example," Best Evidence of Chinese Education, vol. 4, pp. 501-519, 2020.

[17] B. Ganguly, S. B. Dash, D. Cyr, and M. Head, "The effects of website design on purchase intention in online shopping: the mediating role of trust and the moderating role of culture," International Journal of Electronic Business, vol. 8, no. 4-5, pp. 302-330, 2010.

[18] W. Chansanam and U. Detthamrong, "Impact of information behavior online towards customer loyalty in mobile applications in Thailand,"
International Journal of Advanced Science and Technology, vol. 29, no. 4, pp. 654-670, 2010.

[19] M. T. Nuseir, M. N. Akroush, B. Mamoun, and A. Q. Bataineh, "The effect of e-service quality on customers' satisfaction in banks operating in Jordan: An empirical investigation of customers' perspectives," International Journal of Services Economics and Management, vol. 2, pp. 80-108, 2010.

[20] M. Ghasemaghaei and K. Hassanein, "Online information quality and consumer satisfaction: the moderating roles of contextual factors - A meta-analysis," Information \& Management, vol. 52, no. 8, pp. 965-981, 2015.

[21] G. H. Acsai, "Project management of virtual teams: A qualitative inquiry," Master's degree programme in business competence, School of Management University of Tampere, 2016

[22] B. Bruegge and A. H. Dutoit, "Object-oriented software engineering using UML," Patterns and Java. Learning, vol. 5, no. 6, p. 7, 2009.

[23] R. Elmasri and S. B. Navathe. Fundamentals of Database System, 6th ed., USA: Addison-Wesley, 2010.

[24] Z.Wang, "The study of smart phone development based on UML," in Proc. 2011 International Conference on Computer Science and Service System (CSSS), 2011, Nanjing, China, pp. 2791-2794.

[25] B. Dhupia, S. Rubab, and N. Litayem, "Extracting use cases from mobile educational applications requirements," International Journal of Engineering Research \& Technology, vol. 4, no. 4, pp. 883-887, 2015.

[26] A. Seth and K. Seth, Understanding Service-Oriented Architecture: Designing Adaptive Business Model for SMEs, New Delhi, Delhi, India: BPB Publications, 2020.

[27] A. Gill and C. Singh, "Implementation of NTRU algorithm for the security of N-tier architecture," International Journal of Computer Science and Information Technologies, vol. 5, no. 6, pp. 7631-7636, 2014.

[28] T. K. Chiew and S. S. Salim, "Webuse: Website usability evaluation tool," Malaysian Journal of Computer Science, vol. 16, no. 1, pp. 47-57, 2003 .

Copyright (C) 2021 by the authors. This is an open access article distributed under the Creative Commons Attribution License which permits unrestricted use, distribution, and reproduction in any medium, provided the original work is properly cited (CC BY 4.0).

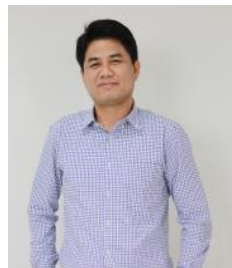

Wirapong Chansanam received his Ph.D. degree in information studies from the Khon Kaen University, Khon Kaen, Thailand. He was with Chaiyaphum Rajabhat University as a lecturer for nine years. In 2019, he joined Khon Kaen University, Khon Kaen, Thailand, where he is currently an assistant professor at the Faculty of Humanities and Social Sciences. His research interests include (but not limited to) information science, especially in digital humanities.

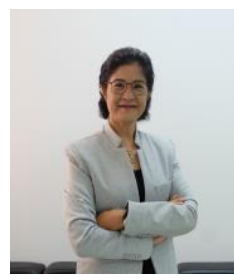

Kulthida Tuamsuk received her D.A. degree in Library and Information Science from Simmons College, U.S.A. She is currently a professor at the Faculty of Humanities and Social Sciences. Her research interests include (but not limited to) information science, smart learning, and digital humanities.

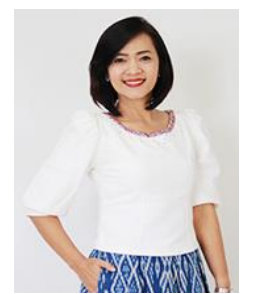

Kornwipa Poonpon received her Ph.D. degree in Applied Linguistics from Northern Arizona University, U.S.A. She is currently an assistant professor at the Faculty of Humanities and Social Sciences. Her research interests include (but not limited to) English, smart learning, and digital technology for education.

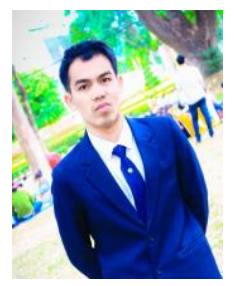

Treepidok Ngootip received a B.BA. degree in Business Computing from the Chaiyaphum Rajabhat University, Chaiyaphum, Thailand. He is currently a master's student at the Faculty of Humanities and Social Sciences, Khon Kaen University, Thailand. 